Mathew, M, Hart, BL and Hayatleh, K

Minimal Power Start-Up Circuit Design for Self-Biased CMOS Current Generators

Mathew, M, Hart, BL and Hayatleh, K (2014) Minimal Power Start-Up Circuit Design for Self-Biased CMOS Current Generators. International Journal of Electronics Letters, 2 (2). pp. 65-71.

doi: $10.1080 / 21681724.2014 .880748$

This version is available: https://radar.brookes.ac.uk/radar/items/77c24c04-fd67-4db9-9706-ce6682c6d224/1/

Available on RADAR: March 2016

Copyright $(C$ and Moral Rights are retained by the author(s) and/ or other copyright owners. A copy can be downloaded for personal non-commercial research or study, without prior permission or charge. This item cannot be reproduced or quoted extensively from without first obtaining permission in writing from the copyright holder(s). The content must not be changed in any way or sold commercially in any format or medium without the formal permission of the copyright holders.

This document is the post print version of the journal article. Some differences between the published version and this version may remain and you are advised to consult the published version if you wish to cite from it. 


\title{
Minimal Power Start-Up Circuit Design for Self-Biased CMOS Current Generators
}

\author{
M. Mathew, B. L. Hart, and K. Hayatleh \\ Oxford Brookes University, Wheatley Campus, Oxford, OX33 1HX, U.K. \\ E-mail:khayatleh@brookes.ac.uk.
}

\begin{abstract}
A new start-up circuit configuration, with minimal standby power dissipation, is proposed for CMOS self-biased current generators. Using standard $0.13 \mu \mathrm{m}$ CMOS technology, simulation results show that for a supply voltage range $1.8 \mathrm{~V}$ to $2.5 \mathrm{~V}$, and a temperature range $-40^{\circ} \mathrm{C}$ to $+85^{\circ} \mathrm{C}$, the circuit standby power dissipation is less than $20 \mathrm{nW}$.
\end{abstract}

Key Words-CMOS Start-up circuit, Current- generator, Self-biased CMOS current generator.

\section{INTRODUCTION}

$\mathrm{T}$ HE self-biased current generator (SBCG) is a circuit scheme widely used for the generation of DC currents that are rail-voltage insensitive and, in some cases, PTAT (Proportional to Absolute Temperature) [1]. However, the SBCG is inherently bi-stable in nature and requires a start-up circuit to guarantee operation in the desired stable mode. Requirements that may be considered essential in a start-up design are that it operates from the same rail voltage as the $\mathrm{SBCG}$, is isolated electrically from the SBCG when the latter is operating correctly and dissipates minimum standby power, certainly significantly less than that of the SBCG itself. Additional desirable requirements are the use of few components, preferably MOSFETS only, and simplicity in circuit design. These two sets of requirements constitute a useful list for a critical comparison of the performance of existing and proposed start-up schemes. A number of such circuits have been described in text books [2],[3] and in the patent literature (see, e.g., [4],[5]). That appearing [3] to satisfy all of the requirements of the list suggested above is discussed initially here. However, the analysis in Section II and simulated performance presented in Section IV below show it to be inferior with respect to standby power to that of a proposed circuit.

In the analysis, the MOSFET symbols and parameters have their usual meanings: thus, e.g, $\left|\mathrm{V}_{\mathrm{TP}}\right|$ is the magnitude threshold voltage of a P-channel device. Additionally for convenience in future discussion, nodal voltages, with respect to earth, are also used: thus the DC and time-dependent voltages at node 4 are, respectively, $\mathrm{V}_{4}$ and $\mathrm{v}_{4}$.

\section{THE COMPARISON CIRCUIT ANALYZED}

In Fig. 1 the circuit configuration within the dashed contour is the start-up circuit [3] to which the proposed circuit is going to be compared. The rest of the circuit comprises an existing type of SBCG producing a rail-voltage-insensitive reference current $I_{0}=V_{4} / R$. The available output currents are $I_{3}$ and $I_{6}$. Ideally $\mathrm{I}_{3}=\mathrm{I}_{6}=\mathrm{I}_{\mathrm{o}}$ but channel length modulation in $\mathrm{T}_{3}$ and $\mathrm{T}_{6}$ causes each of $I_{3}$ and $I_{6}$ to be somewhat greater than $I_{0}$. Briefly, the operation is as follows: if the SBCG does not operate as intended when $\mathrm{V}_{1}\left(=\mathrm{V}_{\mathrm{DD}}\right)$ is applied then $\mathrm{V}_{4}=0$, so $\mathrm{T}_{7}$ is off, and $\mathrm{T}_{8}$ is on because $\left(\mathrm{V}_{\mathrm{DD}-}\left|\mathrm{V}_{\mathrm{TP}}\right|\right)>0$. The gate of $\mathrm{T}_{9}$ is pulled towards $\mathrm{V}_{1}$, consequently $\mathrm{T}_{9}$ switches on and its drain current forces the SBCG into its intended operating mode.

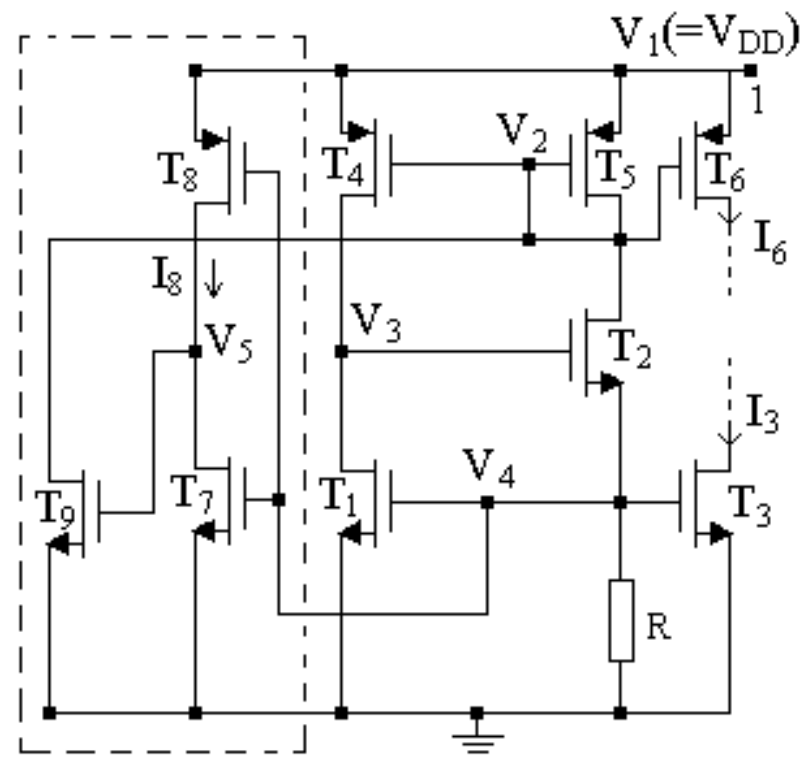

Fig.1 An existing SBCG, with the start-up circuit shown within the dashed contour.

Then $V_{4}=I_{0} R>V_{T N}$, so $T_{7}$ switches on and $V_{5}$ falls below $\mathrm{V}_{\mathrm{TN}}$, thereby cutting off $\mathrm{T}_{9}$ and isolating the start-up circuit from the SBCG. When the SBCG is on and operating correctly the following circuit equations hold.

(1)

$\mathrm{V}_{1} \geq\left(\mathrm{V}_{3}-\mathrm{V}_{\mathrm{TN}}\right)+\mathrm{V}_{\mathrm{SG} 5}$

$\mathrm{T}_{8}$ is on if,

$\mathrm{V}_{1-} \mathrm{V}_{4-}\left|\mathrm{V}_{\mathrm{TP}}\right|>0$

(2) 
Substituting for $\mathrm{V}_{1}$ from (1) into (2),

$$
\mathrm{V}_{1}-\mathrm{V}_{4}-\left|\mathrm{V}_{\mathrm{TP}}\right| \geq \mathrm{V}_{3}-\mathrm{V}_{\mathrm{TN}}+\mathrm{V}_{\mathrm{SG} 5}-\mathrm{V}_{4}-\left|\mathrm{V}_{\mathrm{TP}}\right|
$$

(3)

But, $\left(\mathrm{V}_{3}-\mathrm{V}_{4}\right)=\mathrm{V}_{\mathrm{GS} 2}$ so (3) can be rewritten,

(4)

$$
\mathrm{V}_{1}-\mathrm{V}_{4}-\left|\mathrm{V}_{\mathrm{TP}}\right| \geq\left[\left(\mathrm{V}_{\mathrm{GS} 2}-\mathrm{V}_{\mathrm{TN}}\right)+\left(\mathrm{V}_{\mathrm{SG} 5}-\left|\mathrm{V}_{\mathrm{TP}}\right|\right)\right]
$$

The right hand side of (4) is greater than zero because, if $T_{2}$ and $\mathrm{T}_{5}$ are both on then $\left(\mathrm{V}_{\mathrm{GS} 2}-\mathrm{V}_{\mathrm{TN}}\right)>0$ and $\left(\mathrm{V}_{\mathrm{SG} 5}-\left|\mathrm{V}_{\mathrm{TP}}\right|\right)>0$. The conclusion is that $V_{1}$ cannot be low enough for $T_{8}$ to be off when SBCG is operating correctly. Assuming $T_{8}$ operates in strong inversion its drain current is given by,

$$
\mathrm{I}_{8}=\left(\mu_{\mathrm{p}} \mathrm{C}_{\mathrm{ox}} \mathrm{W}_{8} / 2 \mathrm{~L}\right)\left[\mathrm{V}_{1}-\mathrm{V}_{4}-\left|\mathrm{V}_{\mathrm{TP}}\right|\right]^{2}
$$

(5)

To sink this current, $T_{7}$ must operate in the triode region with $\mathrm{V}_{5}<<\mathrm{V}_{\mathrm{TN}}$ if $\mathrm{T}_{9}$ is to be cut off with minimal sub-threshold drain current, $\mathrm{I}_{9}$. As pointed out in [2] this means $\mathrm{W}_{7}>>\mathrm{W}_{8}$. The standby power dissipation is $\mathrm{P}_{\mathrm{D}}=\left(\mathrm{I}_{8}+\mathrm{I}_{9}\right) \mathrm{V}_{\mathrm{D}} \approx \mathrm{I}_{8} \mathrm{~V}_{\mathrm{DD}}$, as $\mathrm{I}_{8}>>\mathrm{I}_{9}$ because $\mathrm{T}_{8}$ is on and $\mathrm{T}_{9}$ is off. The non-negligible magnitude of $\mathrm{P}_{\mathrm{D}}$ makes this start-up circuit unattractive for use in those systems where power dissipation is required to be minimal.

\section{THE PROPOSED CIRCUIT}

Fig. 2 shows the proposed circuit. In this case, time dependent variables refer to the waveforms describing the switching process in Section IV. Comparison with the configuration of Fig.1, to which it is similar, reveals one apparently small change in that the gate of $\mathrm{T}_{8}$ is not connected to that of $\mathrm{T}_{7}$ but is connected, instead, to the rail voltage, $\mathrm{V}_{\mathrm{DD}}$.

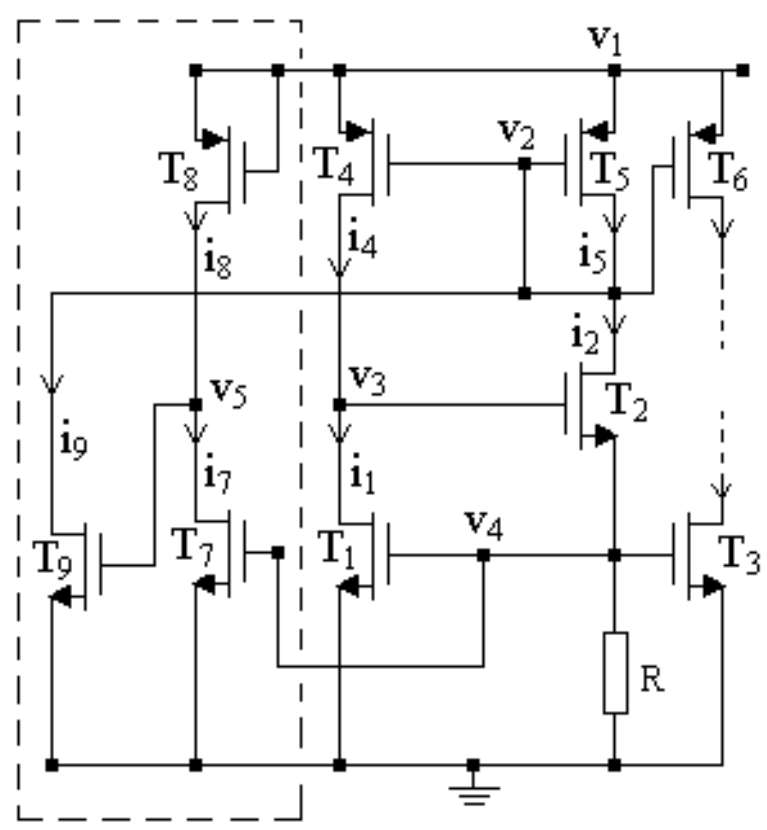

Fig.2 As in Fig.1 the proposed start-up circuit is shown within the dashed contour.

However, the change is not trivial but fundamental, because the design and operation are different. First, $\mathrm{T}_{8}$ and $\mathrm{T}_{7}$ always operate with sub-threshold drain leakage currents; second, as will be seen, a required condition is that $\mathrm{W}_{8}>>\mathrm{W}_{7}$ whereas it is $\mathrm{W}_{7}>>\mathrm{W}_{8}$ for the circuit of Fig.1. It is known [6] that, for a given drain voltage, the sub-threshold drain leakage current of a MOSFET is proportional to the ratio $\mu \mathrm{C}_{\mathrm{ox}} \mathrm{W} / \mathrm{L}$. Thus the drain leakage current of $\mathrm{T}_{8}$ exceeds that of $\mathrm{T}_{7}$ if, for the case $\mathrm{L}_{\mathrm{p}}=\mathrm{L}_{\mathrm{n}},\left(\mu \mathrm{C}_{\mathrm{ox}}\right)_{\mathrm{p}} \mathrm{W}_{\mathrm{P}}>>\left(\mu \mathrm{C}_{\mathrm{ox}}\right)_{\mathrm{n}} \mathrm{W}_{\mathrm{N}}$. Now, for short channel lengths [7], $\left(\mu \mathrm{C}_{\mathrm{ox}}\right)_{\mathrm{p}} \approx\left(\mu \mathrm{C}_{\mathrm{ox}}\right)_{\mathrm{n}} / 4$ so we require $\mathrm{W}_{8}>>4 \mathrm{~W}_{7}$. Using an engineering design factor of 10 to replace the 'much greater' sign the inequality can be met by having $\mathrm{W}_{8} \geq 40 \mathrm{~W}_{7}$. The significance of this choice is clear from Fig.3. Curves A and $\mathrm{B}$ refer respectively, to the $\mathrm{DC}$ characteristics of $\mathrm{T}_{8}$ and $T_{7}$ as a function of $V_{5}$. To cater for the general case the $I_{D}$ axis is not dimensioned. The choice $\mathrm{W}_{8}>\mathrm{W}_{7}$ ensures that curve $\mathrm{A}$ lies well above curve $\mathrm{B}$ up to the intersection point at $\mathrm{V}_{5}=\mathrm{V}_{\mathrm{X}}$ and that $\mathrm{V}_{\mathrm{X}}$ is significantly greater than the gate source voltage $\left(\mathrm{V}_{\mathrm{TN}}\right)$ at which $\mathrm{T}_{9}$ starts conducting. After $\mathrm{V}_{1}$ is applied, the drain voltage of $\mathrm{T}_{7}$ rises towards the $\mathrm{DC}$ equilibrium point $\mathrm{V}_{\mathrm{X}}$. However, $\mathrm{T}_{9}$ switches on when its gate voltage reaches $\mathrm{V}_{\mathrm{TN}}$ and activates the SBCG. As in the case of Fig. 1 the gate voltage of $T_{1}$, now at $V_{4}=I_{0} R$, switches on $T_{7}$, causing $\mathrm{T}_{9}$ to cut off and isolate the start-up circuit from the SBCG. The standby power dissipation of the start-up circuit is now minimal because only sub-threshold drain current leakage currents flow in $\mathrm{T}_{7}, \mathrm{~T}_{8}$ and $\mathrm{T}_{9}$.

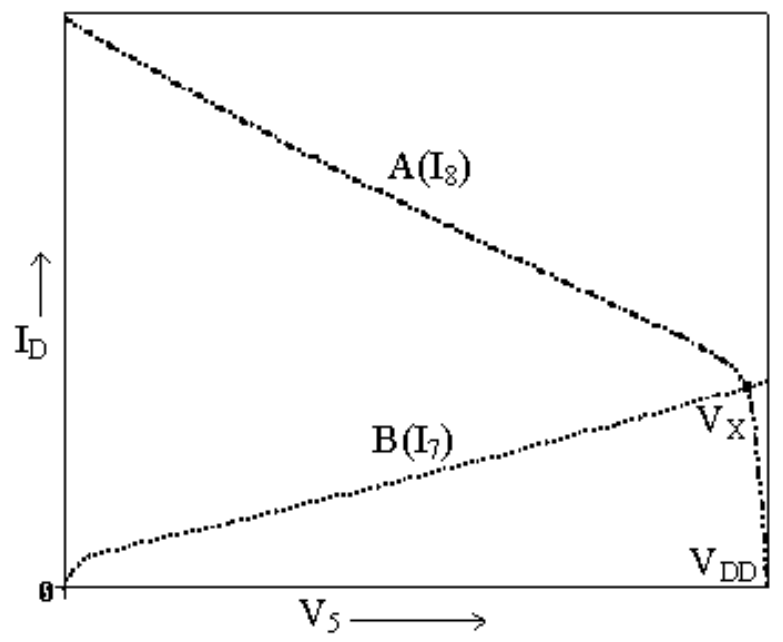

Fig. 3 Curves A and B refer, respectively, to the DC characteristics of $\mathrm{T}_{8}$

\begin{tabular}{|c|c|c|c|}
\hline \multicolumn{4}{|c|}{ TABLE I } \\
\hline \multicolumn{4}{|c|}{ POWER DISSIPATION $\left(\mathrm{P}_{\mathrm{D}}\right)$ DATA FOR FIGS. 1,2} \\
\hline & & \multicolumn{2}{|c|}{$\mathrm{V}_{\mathrm{DD}}(\mathrm{V})$} \\
\hline & $\mathrm{T}\left({ }^{\circ} \mathrm{C}\right)$ & 1.8 & 2.5 \\
\hline \multirow{3}{*}{$\begin{array}{l}\mathrm{P}_{\mathrm{D}} \text { (start-up } \\
\text { circuit) } \\
\text { Fig.1 }\end{array}$} & -40 & $375 \mu \mathrm{W}$ & $1056 \mu \mathrm{W}$ \\
\hline & +27 & $303 \mu \mathrm{W}$ & $951 \mu \mathrm{W}$ \\
\hline & +85 & $253.14 \mu \mathrm{W}$ & $888.20 \mu \mathrm{W}$ \\
\hline \multirow{3}{*}{$\begin{array}{l}\mathrm{P}_{\mathrm{D}} \text { (start-up } \\
\text { circuit) } \\
\text { Fig.2 }\end{array}$} & -40 & $48.24 \mathrm{pW}$ & $96.15 \mathrm{pW}$ \\
\hline & +27 & $1.33 \mathrm{nW}$ & $2.51 \mathrm{nW}$ \\
\hline & +85 & $9.08 \mathrm{nW}$ & $16.50 \mathrm{nW}$ \\
\hline \multirow{2}{*}{$\begin{array}{l}\mathrm{P}_{\mathrm{D}} \text { (current } \\
\text { generator) }\end{array}$} & -40 & $360.23 \mu \mathrm{W}$ & $550.16 \mu \mathrm{W}$ \\
\hline & +27 & $369.16 \mu \mathrm{W}$ & $560.44 \mu \mathrm{W}$ \\
\hline
\end{tabular}
and $\mathrm{T}_{7}$ in Fig.2.

IV. RESULTS AND DISCUSSION 
Figs. 1,2

$+85$

$378.05 \mu \mathrm{W}$

$572.62 \mu \mathrm{W}$

The circuits of Fig.1 and Fig. 2 were simulated using CADENCE PSpice Level 7 parameters.

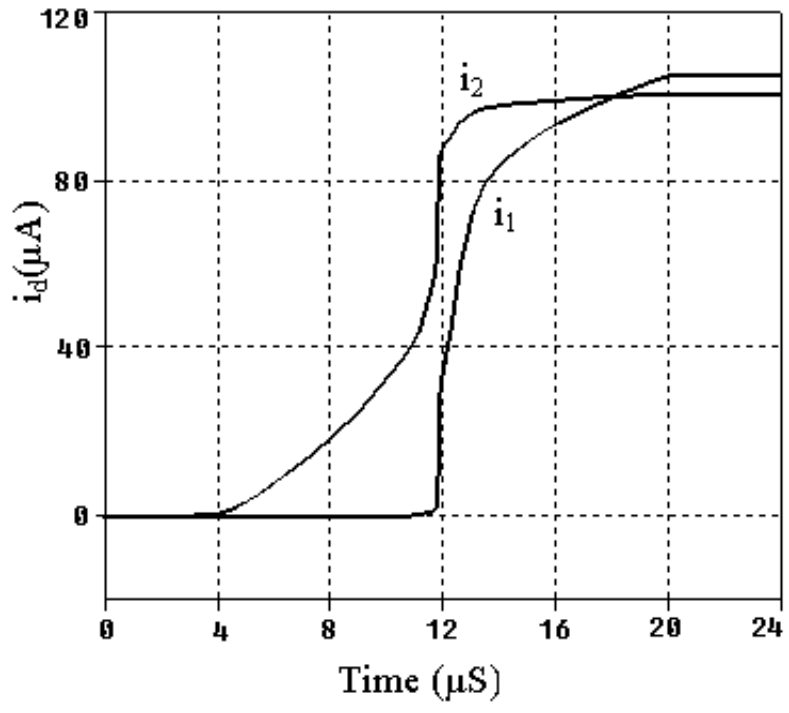

Fig. 4 Current waveforms for Fig. $2: \mathrm{T}=27^{\circ} \mathrm{C}$.

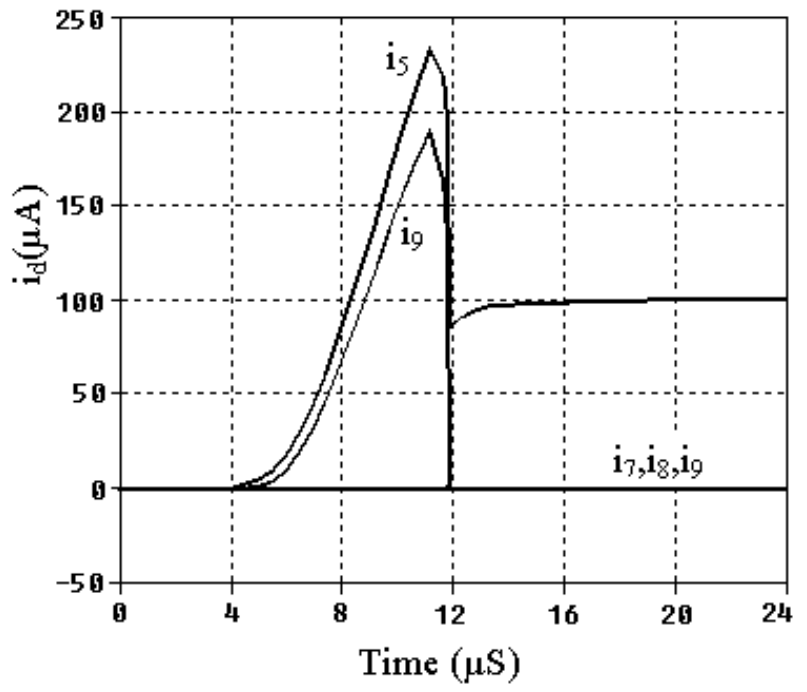

Fig. 5 Further current waveforms for Fig. 2 : $\mathrm{T}=27^{\circ} \mathrm{C}$.

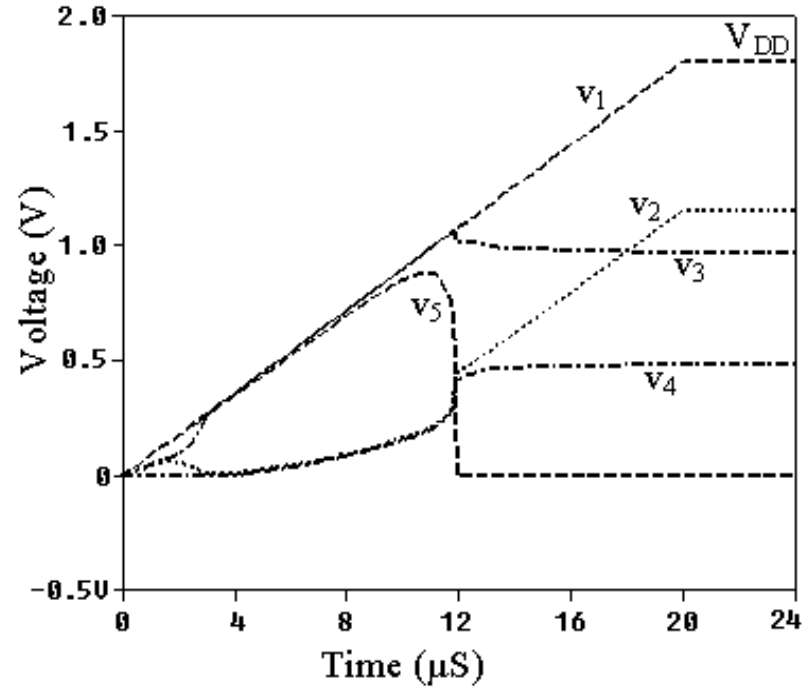

Fig.6 Voltage waveforms for Fig.2: $\mathrm{T}=27^{\circ} \mathrm{C}$.

$\mathrm{V}_{\mathrm{DD}}$ was chosen to be $1.8 \mathrm{~V}$ and $\mathrm{I}_{\mathrm{o}}$ to be $100 \mu \mathrm{A}$ for which $\mathrm{R}=4.8 \mathrm{k} \Omega$, corresponding to $\mathrm{V}_{4}=0.48 \mathrm{~V}$. For all the MOSFETs $\mathrm{L}=0.13 \mu \mathrm{m}$; for both circuits $\mathrm{W}_{1}=\mathrm{W}_{2}=\mathrm{W}_{4}=\mathrm{W}_{5}=\mathrm{W}_{6}=5 \mu \mathrm{m}$ and $\mathrm{W}_{9}=1 \mu \mathrm{m}$; for Fig. $1, \mathrm{~W}_{7}=40 \mu \mathrm{m}$ and $\mathrm{W} 8=1 \mu \mathrm{m}$, whereas for Fig. $2, \mathrm{~W}_{7}=1 \mu \mathrm{m}$ and $\mathrm{W}_{8}=40 \mu \mathrm{m}$. The choice $\mathrm{W}=40 \mu \mathrm{m}$ satisfies the suggested design choice mentioned in Section III. DC tests were made to determine $\mathrm{V}_{\mathrm{X}}$ in Fig. 3 and the start-up power dissipation, $\mathrm{P}_{\mathrm{D}}(\mathrm{su})$ and the $\mathrm{SBCG}$ power dissipation, $\mathrm{P}_{\mathrm{D}}(\mathrm{cg})$ for the circuits of Fig. 1 and Fig. 2 for the temperature range $+85^{\circ} \mathrm{C} \geq \mathrm{T} \geq-40^{\circ} \mathrm{C}: \quad \mathrm{T}=27^{\circ} \mathrm{C}$ is taken to represent room temperature. It was established that $\mathrm{Vx}>1.4 \mathrm{~V}$ for $\mathrm{V}_{\mathrm{DD}}=1.8 \mathrm{~V}$ and $\mathrm{Vx}>1.77 \mathrm{~V}$ for $\mathrm{V}_{\mathrm{DD}}=2.5 \mathrm{~V}$. Power dissipation data is presented in Table 1 . The case $\mathrm{V}_{\mathrm{DD}}=2.5 \mathrm{~V}$ was simulated to show the increase in $\mathrm{P}_{\mathrm{D}}(\mathrm{su})$ for Fig.1 compared with that of Fig.2 when $V_{D D}$ was increased. The comparative constancy of $I_{0}$ with variation $V_{D D}$ and $T$, a characteristic of the SBCG for the case of a temperature-independent $\mathrm{R}$ (assumed here) accounts for the $\mathrm{P}_{\mathrm{D}}(\mathrm{cg})$ figures shown.

It is clear that $\mathrm{P}_{\mathrm{D}}(\mathrm{su})$ is significantly lower for the proposed circuit than that of Fig. 1 for $\mathrm{V}_{\mathrm{DD}}=1.8 \mathrm{~V}$. The start-up circuit of Fig.1 is obviously inappropriate because its power dissipation is comparable with that of the SBCG at $\mathrm{V}_{\mathrm{DD}}=1.8 \mathrm{~V}$ and exceeds it for $\mathrm{V}_{\mathrm{DD}}=2.5 \mathrm{~V}$. The operation of the proposed startup circuit in Fig.2 is clarified by cross-referencing the drain current waveforms of Fig.4,5 with the voltage waveforms of Fig.6. To obtain these waveforms the power supply rail $\left(\mathrm{v}_{1}\right)$ was applied in the form of a continuous train of trapezoidal voltage pulses with base level zero, amplitude $\mathrm{V}_{\mathrm{DD}}$, voltagelevel transition times $t_{t}$, and a pulse duration $t_{d}\left(>>t_{t}\right)$. As $t_{t}$ is not known to the designer beforehand, four widely spaced values of $t_{t}$ were used in simulation tests: $20 \mathrm{~ns}, 20 \mu \mathrm{s}$ (that shown), $2 \mathrm{~ms}$ and $2 \mathrm{~s}$. Following the application of $\mathrm{v}_{1}$ at $\mathrm{t}=0, \mathrm{v}_{5}$ rises as the current $\left(\mathrm{i}_{8}-\mathrm{i}_{7}\right)$ charges up the capacitance associated with the gate of $\mathrm{T}_{9}$ and $\mathrm{i}_{9}$ rises from a subthreshold level, at about $t=4 \mu$ s when $v_{5}>V_{T N}$. Then $i_{9}$ rises to a peak, the duration of which depends on the time taken for the SBCG, and hence $T_{7}$ to switch on. The switch-on process involves a regenerative feedback action that causes a jump in 
$i_{1}$ and is responsible for the fast trailing edge of $i_{9}$. Note that $i_{2}$ leads $i_{1}$; that is because $T_{1}$ cannot switch on until the potential difference $i_{2} R$ exceeds $V_{T N}$. The drain currents $i_{7}, i_{8}$, and $i_{9}$ after $t=12 \mu \mathrm{s}$, appear to lie on the current axis because they are too small to register on the current scale used. When the SBCG is on, $I_{1}$ is slightly different from $I_{2}\left(=I_{0}\right)$, despite the fact that $\mathrm{W}_{4}=\mathrm{W}_{5}$, because their drain-source voltages are different. Tests for $t_{t}=20 n s, t_{t}=2 m s$ and $t_{t}=2 s$ produced waveforms similar in shape to those of Fig.4,5 and Fig. 6 but with different time scales. The energy consumed by the startup circuit in switching on the SBCG, estimated from the product $V_{D D} \times \int_{t=4 \mu s}^{t=12 \mu s} i_{9} d t$ is approximately $1 \mathrm{~nJ}$.

\section{CONCLUSIONS}

A list of requirements has been suggested for comparing the performance of existing and proposed start-up circuits for selfbiased current generators (SBCG). An important requirement of the list is minimum standby power because once the SBCG is on and operating correctly the start-up circuit performs no useful function.

A new start-up configuration has been presented and shown to meet all the requirements of the list. The standby power dissipation, in the $\mathrm{nW}$ range, has been shown to be minimal and current and voltage waveforms have been obtained to illustrate circuit operation

Although the design dealt with a particular SBCG and particular values of $\mathrm{V}_{\mathrm{DD}}$ and $\mathrm{I}_{0}$, the configuration can be considered universal in that it can be used, or adapted for use, with other types of SBCG (see e.g,[1]) and other value of $I_{0}$ and $\mathrm{V}_{\mathrm{DD}}$ provided the MOSFETs employed have the appropriate voltage ratings and associated channel lengths.

\section{ACKNOWLEDGMENT}

The authors thank Professor F. J Lidgey of Oxford Brookes University, Oxford, U.K, for helpful comments during the course of the work described.

\section{REFERENCES}

[1] M. Mathew, B.L Hart, and K. Hayatleh, " Rail-supply insensitive CMOS current generator," International Journal of Electronics, Nov.2012, Vol.99, No.11,pp 1569-1574.

[2] P.E Allen and D.R Holberg, Chapter 4, in CMOS Analog Circuit Design, $2^{\text {nd }}$ Edition, Oxford University Press, 2002, pp149-150.

[3] P.R Gray, P.J Hurst, S.H Lewis, R.G Meyer, Chapter 4, in Analysis and Design of Analog Integrated Circuits, $5^{\text {th }}$ Edition, John Wiley and Sons Inc, 2010, pp310.

[4] Chang-Yang Hsiao, "Current bias circuit and current bias start-up circuit thereof," U.S Patent US7,342,439 B2, March 11,2008.

[5] A. Stellberger and F. Schwiderski , "Start-up circuit for band-gap voltage reference generators," U.S Patent US2011/0006749 A1, Jan. 13, 2011.

[6] F. Fallah, and M. Pedram), "Standby and active leakage current control and minimization in CMOS VLSI circuits," IEICE Transactions on Electronics, April 2005,Vol.E88-C,No.4, pp 509-519.

[7] T.C Carusone , D.A Johns and K.W Martin, Chapter 1, in Analog Integrated Circuit Design, $2^{\text {nd }}$ Edition, John Wiley and Sons,2013, p54. 